\title{
Building Information Modelling and Standardised Construction Contracts: a Content Analysis of the GC21 Contract
}

\author{
Aaron Manderson, Marcus Jefferies and Graham Brewer \\ School of Architecture and Built Environment, University of Newcastle, Australia
}

\begin{abstract}
Building Information Modelling (BIM) is seen as a panacea to many of the ills confronting the Architectural, Engineering and Construction (AEC) sector. In spite of its well documented benefits the widespread integration of BIM into the project lifecycle is yet to occur. One commonly identified barrier to BIM adoption is the perceived legal risks associated with its integration, coupled with the need for implementation in a collaborative environment. Many existing standardised contracts used in the Australian AEC industry were drafted before the emergence of BIM. As BIM continues to become ingrained in the delivery process the shortcomings of these existing contracts have become apparent. This paper reports on a study that reviewed and consolidated the contractual and legal concerns associated with BIM implementation. The findings of the review were used to conduct a qualitative content analysis of the GC21 $2^{\text {nd }}$ edition, an Australian standardised construction contract, to identify possible changes to facilitate the implementation of BIM in a collaborative environment. The findings identified a number of changes including the need to adopt a collaborative contract structure with equitable risk and reward mechanisms, recognition of the model as a contract document and the need for standardisation of communication/information exchange.
\end{abstract}

Keywords: Building information modelling, contracts, legal risks, procurement, qualitative content analysis.

Paper type: Research article

\section{Introduction}

The Architectural, Engineering and Construction (AEC) sector is often characterised as fragmented, highly complex and risk adverse with high levels of conflict and low levels of productivity (Keung and Shen, 2013; Phua and Rowlinson, 2004; Royal Commission into the Building and Construction Industry, 2002). Reviews of the sector such as the Egan Report (1998) in the United Kingdom (UK) and the New South Wales Government's (1998) green discussion paper on information technology (IT) in construction clearly identify the need for the AEC sector to innovate, particularly with the adoption of technological solutions to address existing shortcomings. The NSW discussion paper focused on the possible productivity benefits in the adoption of IT for specific tasks and a rethink of the project information delivery process. However, many of the recommendations made in this discussion paper failed to gain traction and the existing information management processes have remained in place (Beard, 2006). Ironically, the emergence of Building Information Modelling (BIM) has again triggered an analysis of existing work practices and processes with the overarching question - are there better ways of managing project information?

\footnotetext{
Copyright: Construction Economics and Building 2015. (C) 2015 Aaron Manderson, Marcus Jefferies, and Graham Brewer. This is an Open Access article distributed under the terms of the Creative Commons Attribution 4.0 Unported (CC BY 4.0) License (https://creativecommons.org/licenses/by/4.0/), allowing third parties to copy and redistribute the material in any medium or format and to remix, transform, and build upon the material for any purpose, even commercially, provided the original work is properly cited and states its license.
}

Citation: Manderson, A., Jefferies, M. and Brewer, G., 2015. Building information modelling and standardised construction contracts: a content analysis of the GC21 contract, Construction Economics and Building, 15(3), 72-84. DOI: http://dx.doi.org/10.5130/AJCEB.v15i3.4608

Corresponding author: Aaron Manderson; Email - c9039148@uon.edu.au

Publisher: University of Technology Sydney (UTS) ePress 
While the term BIM is relatively new, the underlying concept emerged in the mid 1960's in conjunction with the development of early Computer Aided Drafting (CAD) technology (Eastman et al., 2011). The concept has now evolved to a point where there are three key terms associated with BIM: Building Information Model, Building Information Modelling and Building Information Management. While there is no consensus on the definitions of these terms, they do represent separate but linked functions in the project delivery process. Using the definitions as proposed by BuildingSMART (2012):

- Building Information Model is considered a DIGITAL REPRESENTATION of the physical and functional characteristics of a facility.

- Building Information Modelling is a BUSINES PROCESS for generating and leveraging building data to design, construct and operate the building during its lifecycle.

- Building Information Management is the ORGANISATION and CONTROL of the business process by utilising the information in the digital prototype to effect the sharing of information over the entire lifecycle of an asset.

\section{Legal and Contractual Concerns with BIM Deployment}

In spite of the documented benefits, the implementation of BIM in the AEC Sector remains sporadic (Arayici et al., 2011; Becerik-Gerber and Kensek, 2010). Significant effort, both within Australia and internationally has gone into justifying the business case for BIM adoption (Aranda-Mena et al., 2009; Bryde, Broquetas and Volm, 2013; Duyshart et al., 2003; McGraw Hill Construction, 2014), but other challenges do exist beyond the cost and technological barriers. The legal challenge associated with BIM implementation is another barrier that has received widespread attention (Ashcraft, 2008; Built Environment Industry Innovation Council, 2010; Kuiper and Holzer, 2013; Larson and Golden, 2007; Sebastian, 2011).

Research concentrating on BIM legal issues has focused on two key aspects, firstly identifying the legal issues (Ashcraft, 2008; Larson and Golden, 2007; McAdam, 2010) and also the most appropriate procurement method and framework for delivering a BIM enabled project (Ashcraft, 2008; Grilo and Jardim-Goncalves, 2011; Kuiper and Holzer, 2013; Porwal and Hewage, 2013). There has however been limited research into the interaction between the BIM legal issues and the procurement method beyond recommending a relationship based approach. Further, current standard contracts lag behind technological developments and therefore do not address the emerging legal risk facing the project team (Hartmann and Fischer, 2008). This research focuses on the interaction between BIM and contracts to identify possible changes to contract mechanisms that allows for an integrated deployment of BIM (see Figure 1 in 'Research Methodology' section of this paper).

\section{Compensation and consideration}

This area refers to the ability of the various participants to reclaim the costs associated with BIM technology such as the purchasing of software, hardware and training. It also identified the need to ensure the various parties are justly compensated for the additional effort and risk that BIM has introduced into the design process. For example, the increased detail incorporated into the Model requires additional effort and increases exposure to liability for design errors. Current payment models are based on the production of two dimensional drawings that show design intent rather than realistic digital representations of a facility (Arensman and Ozbek, 2012; Ashcraft, 2008; Wheatley and Brown, 2007).

\section{Conditions of contract}

To enable the implementation of BIM in a conducive environment, a number of changes are required to the conditions of contract that focus on the type of contractual relationships, 
modelling deliverables, collaboration in the e-environment and appropriate punitive measures for nonperformance. A collaborative environment is considered the most advantageous contractual relationship for implementing BIM where stakeholders can input information in a situation that is not adversarial. The contract needs to clearly articulate the modelling deliverables such as what and when information is to be available for review and distribution. The status of econtracting should be addressed and details provided of who can make changes and approve digital information. Finally, a range of punitive measures can be included in the conditions as a consequence of any stakeholders not adhering to the contract obligations (Hurtado and O'Connor, 2008; Rezgui, Beach and Rana, 2013; Thomson and Miner, 2006).

\section{Data security}

The shift towards e-communication has triggered concerns regarding appropriate levels of project data security and protection. For example, ensuring data is protected against corruption, loss and manipulation, detailing restrictions on data sharing and access and requiring a certain level of insurance to cover any possible financial losses associated with breeches of data security (CRC Construction Innovation, 2008; Hurtado and O'Connor, 2008; Sweet and Schneier, 2013).

\section{Intellectual property}

Protection of intellectual property (IP) rights is a major concern for the various stakeholders involved in the design process. Protecting the IP of the design and the data embedded in the model are critical for maintaining designer confidence in the process. This includes confidential information and trade secrets such as construction techniques and sequencing. Addressing IP in a collaborative environment increases the complexity of IP allocation (Azhar, Khalfan and Masqsood, 2012; Kog, 2010; Larson and Golden, 2007; Olsen and Taylor, 2010; Porwal and Hewage, 2013).

\section{ICT protocols processes and responsibilities}

BIM implementation requires two levels of language, one for describing the actual technical implementation and one that details the contractual processes such as high level workflows. For example, describing change management processes and milestone submissions and outlining the various responsibilities and protocols for BIM integration ensures the process is managed in an efficient manner. This includes a clear communication structure for confirming project requirements and change. Finally, the execution plan can be referenced as a contract document but should be left to the various participants to determine the day to day technical implementation requirements (Greenwood, Lewis and Lockley, 2010; Haynes, 2009a; Larson and Golden, 2007; McAdam, 2010; Rezgui, Beach and Rana, 2013).

\section{Interoperability}

Similar to protocols and processes, interoperability can be described at a technical and workflow level. Due to the ongoing AEC sector's concerns regarding limited software compatibility, interoperability between systems is considered a key legal issue. Critical to achieving interoperability is describing the process for data transfer between project stakeholders and assigning responsibility for managing, monitoring and auditing the process. The actual technological compatibility requirements can be referenced in the BIM execution plan (Amor and Faraj, 2001; Ashcraft, 2008; Holzer, 2007; Hurtado and O'Connor, 2008; Jensen and Jóhannesson, 2013; Simonian and Korman, 2010).

\section{Legislation and judicial precedence}

The Australian AEC sector is highly regulated through a combination of Federal and State Acts and Regulations that apply to all facets of the construction process (Bailey and Bell, 2011). With 
the advent of digital communication and project teams operating in separate countries, determining what legislative jurisdiction the contract will operate under is the first consideration when using BIM. The contract needs to permit e-contracting and e-communication that will ensure the project can occur in a digital environment. Other issues requiring consideration include Privity, whereby a contract cannot impose obligations or rights to any persons outside of the parties involved in the contract. In addition, determining the level of third party reliance or the ability for others to rely on the information embedded in the Models that are not party to the contract needs to be addressed in the Contract. Finally, for public sector projects, appropriative details on how the project information will be archived in a format that can be easily accessed in the future need to be considered when requesting any 'as-built' documentation from the Contractor (Hurtado and O'Connor, 2008; Kog, 2010; Larson and Golden, 2007; O'Brien, 2007; Sebastian, 2010).

\section{Professional liability}

Professional Indemnity (PI) is a major concern for design professionals involved in BIM, especially a collaborative environment. By default, these professionals become liable for the design contributions of non-professionals, including automatic changes by software. Also, some jurisdictions mandate that licensed professionals are in charge of the design process. Therefore, design delegation to non-professionals, subcontractors and the effect of software that automatically updates the design need to be considered. Appropriate PI insurance that includes BIM risk is highly recommended (Ashcraft, 2008; Greenwood, Lewis and Lockley, 2010; Hurtado and O'Connor, 2008; Khosrowshahi and Arayici, 2012; Olsen and Taylor, 2010; Rezgui, Beach and Rana, 2013).

\section{Public sector agency}

Legislative controls typically require the submission of project document to various Public Agencies for approval. Many of these agencies are not equipped to process digital models and therefore require hardcopy plans for review and approval. Further, the legislation requires the approvals to be in writing, such as 'stamped' drawings and specifications, stored onsite during construction. Finally, Agencies use the stamped documents as a reference for compliance inspections during construction and there may be discrepancies between the digital Model, the plans and the actual sequence of works. (Allen and Helms, 2006; Ashcraft, 2008; McAdam, 2010; Rezgui, Beach and Rana, 2013; Wong, Wong and Nademm, 2011).

\section{Risk allocation}

The final legal concern is the allocation of risk between various project stakeholders. There is an inherent risk to the designer for documenting the project in BIM and then distributing the digital model to the Contractor to use as a basis for construction. Detailing a model requires a significant amount of effort for very little reward. Relationship based contracting allows for this risk to be fairly attributed to all project stakeholders that ensures the maximum benefit is obtained from using BIM. Finally appropriate project risk insurance is recommended to cover the various risks and liabilities (Anumba and Ruikar, 2002; Arensman and Ozbek,2012; Ashcraft, 2008; Larson and Golden, 2007; Porwal and Hewage, 2013; Simonian and Korman, 2010).

\section{Standardised construction contracts}

A construction contract can be defined as "any contract where one person [or corporation] agrees for a value consideration to carry out construction works which may include building or engineering works for another" (Loots and Charrett, 2009 p.23). Over time construction contracts have taken on the role of manuals for managing construction process. Some of the benefits of standard contracts include allowing for certainty in risk allocation, familiarization with 
procedures and the means of recording the business deal (Hughes and Greenwood, 1996). A Construction contract typically contains several documents: the Contract Form, Conditions of Contract Drawings, Drawings, Specifications, Appendices, Bill of Quantities. Each document within the Contract serves a specific purpose, and these roles are briefly described in Table 1.

Table 1: Purpose of contract documents

\begin{tabular}{|c|c|}
\hline Document & Description/Purpose \\
\hline $\begin{array}{l}\text { Completed } \\
\text { Contract Form }\end{array}$ & $\begin{array}{l}\text { The signed agreement that sets out the specific contract information and provides a full list } \\
\text { of the contract documents. }\end{array}$ \\
\hline $\begin{array}{l}\text { Conditions of } \\
\text { Contract }\end{array}$ & $\begin{array}{l}\text { The rules and procedures that dictate the behaviours of the various parties to the contract. } \\
\text { May include amended conditions that specifically related to the project. }\end{array}$ \\
\hline Drawings & $\begin{array}{l}\text { A graphical representation of the work that is to be completed usually in the form of plans, } \\
\text { elevations, sections and details and prepared for a specific purpose such as architectural, } \\
\text { structural electrical or landscaping. }\end{array}$ \\
\hline Specification & $\begin{array}{l}\text { A written description of the work to be completed focusing on the standard of } \\
\text { workmanship and the quality of the materials that complement the drawings. }\end{array}$ \\
\hline Appendices & $\begin{array}{l}\text { Other relevant documents such as environmental approvals or investigations, geotechnical } \\
\text { investigations, post tender communication. }\end{array}$ \\
\hline Bill of Quantities & $\begin{array}{l}\text { A document that lists the estimated quantities of the work usually in accordance with some } \\
\text { form of recognized standard. }\end{array}$ \\
\hline
\end{tabular}

BIM has the potential to replace certain contract documents, for example the drawings, specifications or other written information that is based on data typically embedded in the design (Olsen and Taylor, 2010). However, as Eastman (cited in Hartmann and Fischer, 2008) points out, the conditions of contract need to reflect the changing status of digital information and the use of BIM in the project delivery process.

The integration of BIM into a collaborative project delivery method and also the inclusion of the Model as a contract document have the potential to deliver increased productivity and quality to AEC sector providing the various legal issues are adequately addressed in the contract conditions. Contract addendums have emerged that address some of the legal challenges, for example the ConsensusDOC 301- BIM Addendum (Lowe and Muncey, 2009) and the American Institute of Architect's E202 "Building Information Modelling Protocol Exhibit" (Haynes, 2009b). In addition, the Chartered Institute of Building (CIOB) has included specific BIM clauses in the latest release of its contract for complex projects (Chartered Institute of Building, 2013). However, there has been limited published contract analysis that compares the various BIM generated legal issues against standard conditions in order to determine the changes needed to facilitate BIM implementation and the use of the Model as a contract document. This research therefore focuses on filling that gap by undertaking an analysis of the Conditions of Contract in a systematic qualitative manner that identifies the changes needed to enable full integration of BIM in the project delivery process.

\section{Research Methodology}

This research has two key objectives, firstly developing a tool that identifies the changes needed to standard contracts to enable BIM integration and secondly, the application of the tool on a current standardised contract. Based on the two objectives there are two stages to this investigation:

- Stage 1 is the formation of the tool using a recognized analysis method, and

- Stage 2 is the selection and analysis of a standardised contract using the BIM analysis tool.

Boyatzis (1997 p. 4) defines thematic analysis as a "process for encoding qualitative information. This may be a list of themes; a complex model of themes, indicators and qualifications that are 
casually related, or something in between these two forms". At its simplest, a theme is a pattern, which delineates and organises potential observations and at its most complex, interprets certain aspects of the topics under investigation. For this research, the themes are generated inductively from the literature and deductively from previous research and thematic investigations. In addition, the thematic grouping uses a combination of directly observable data and underlying phenomena, which relate to the legal implications of BIM implementation.

Drawing on the previous thematic identification undertaken by Ashcraft (2008); McAdam (2010); and Kuiper and Hulzer (2013), ten themes (see Figure 1) were identified comprising a combination of both manifest and latent issues. The themes were grouped in this form to allow for a qualitative analysis of the issues affecting BIM integration into construction projects. Using such an approach enables the condensing of a vast array of legal issues which have been identified from various sources such as trade literature, books, journal articles, the internet and government agencies.

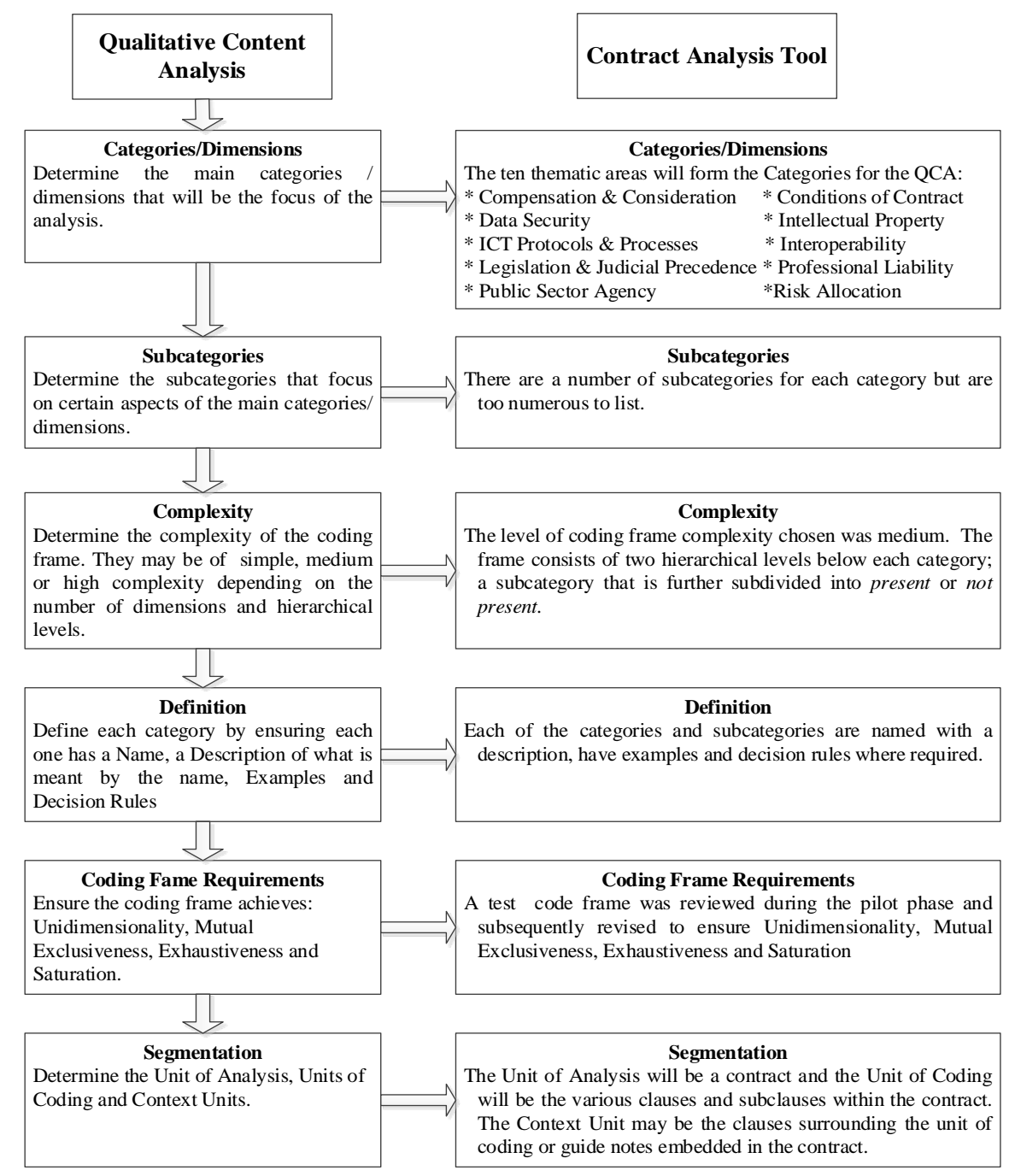

Figure 1: Qualitative content analysis tool

\section{Stage 1: Qualitative content analysis}

This investigation applies Qualitative Content Analysis (QCA) as the method for identifying the contractual changes needed to implement BIM in the project setting. Content Analysis (CA) is described as a "research method that uses a set of procedures to make valid inferences from text" (Weber, 1990p. 9). Traditionally applied quantitatively, CA is used to determine the 
frequency specific words or phrases appear in a text and as a means of comparing and contrasting communication content against set objectives and to trace cultural patterns (Berelson, 1971). QCA adapts the systematic nature of CA to describe the meaning of qualitative material (Schreier, 2013). The main differences between CA and QCA are how the categories are generated and applied to the data, the analysis process and how the results can incorporate the latent meaning of the data (Mayring, 2004). Figure 1 shows the preliminary phases of the QCA process for developing the Coding Frame, prior to the actual data analysis. The Categories and Subcategories were formed using a combination of concept and data driven generation, they were constructed using the literature review and BIM relevant categories emanating from contract but not identified in the literature (Schreier, 2013). Figure 2 is an illustration of the Coding Frame intent, minus the subcategories.

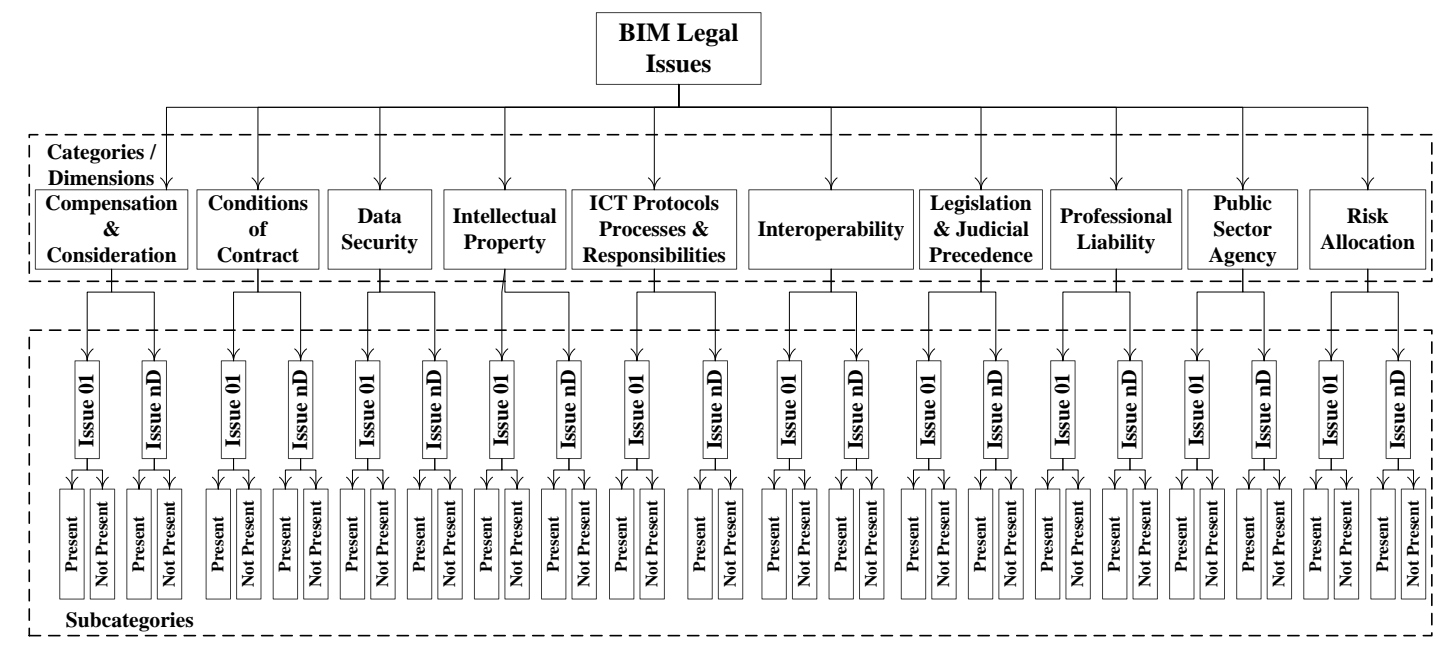

Figure 2: Qualitative content analysis structure

\section{Stage 2: The case - standardised contract GC21}

The selected Case is the New South Wales (Australia) Government GC21 2nd edition General Conditions of Contract. The Analysis is only be applied to the standard sections of the contract and not to a specific contract. This contract is widely used by NSW Public Sector Agencies for construction contracting and is suitable for works valued at $\$ 1$ million or more or works of a lower value but with complex contractual requirements (New South Wales Procurement, 2012). The evolution of GC21 contract can be traced back to the 1992 NSW Government's Royal Commission into productivity in the Construction Industry that identified the need for a cooperative form of construction contracting. Initially named the ' $\mathrm{C} 211 \mathrm{st}$ edition', this contract has gone through several revisions, culminating in the latest GC21 2nd Edition (NSW Department of Commerce, 2012).

The structure of the GC21 does not differentiate between the traditional 'construct only' or 'design and construct' procurement methods. The Contract adopts the stance that the Contractor will always have some level of responsibility for completing the design. The Contract therefore only details the level of design the Contractor must complete, ranging from pure design and construct through to the completion of 'shop' or detail drawings. This approach avoids the need for separate 'construct only' and 'design and construct' contract forms and the design ambiguity typically associated with these two procurement methods (NSW Department of Commerce, 2012). The Contract adopts a somewhat traditional structure consisting of:

- Conditions of Tendering;

- Tender Schedules including the Tender Form;

- General Conditions of Contract and Contract Information; and

- Preliminaries. 
There are also extensive notes and commentary that provide guidance on drafting and administering the contract and a detailed Contractor Performance Reporting mechanism that is used to monitor and manage the performance of the Contractor during the life of the contract.

\section{Results}

Table 2 presents a summary of the QCA results. The critical findings for each of the categories are briefly discussed including the absence or presence of certain subcategories and a summary of some of the possible changes required to the contract to enable BIM integration.

Table 2: Summary of QCA results

\begin{tabular}{ll}
\hline Category & Description \\
\hline Compensation & $\begin{array}{l}\text { The Contract only describes the Contractor/Principal payment protocol. Therefore, the Contract is silent } \\
\text { on the ability of the Contractor to claim for BIM implementation costs. The ability to recoup these costs } \\
\text { would be subject to commercial tension in the tendering process and the amount the Contractor includes in } \\
\text { its tender price. The conditions do not limit the Principal for setting performance payments or equable risk } \\
\text { and reward distribution, but there is no guidance in the supporting material describing appropriate } \\
\text { mechanisms. } \\
\text { Conditions of }\end{array}$ \\
$\begin{array}{l}\text { The contract adopts a hybrid Traditional/Design and Build approach that encourages cooperation between } \\
\text { the various contract parties but does not extend to a relationship system. The contract does not } \\
\text { acknowledge the existence of a Model or BIM specific deliverables, however mechanisms do exist within the } \\
\text { conditions to include such items. E-collaboration is limited to the transmission of information and does not } \\
\text { address the issues associated with electronic contracting. There are a limited number of conditions that need } \\
\text { to be coordinated with the head contract, none relating to BIM conditions. There are punitive measures for } \\
\text { non-performance, plus positive reinforcement for using BIM in design as part of the Contractor } \\
\text { Performance Reporting System }\end{array}$
\end{tabular}

Data Security Each party to the contract is responsible for the protection of its data. Additional protections exist for confidential or sensitive data. There are no mandatory requirements for the Contractor to have insurance for the loss or corruption of data.

Intellectual As this is a Public Sector contract, all IP created during the project remains with the Principal, irrespective of Property the design environment. A single use design license is issued to the Contractor and information deemed confidential is protected by data security clauses. There is no mention of Model ownership or design components.

ICT Protocols There are change management and communication protocols detailed in the contract based on the Processes and traditional procurement methods. The contract details the responsibilities for managing change and what is Responsibilities to be included in any claim or submission. The contract does not mention the suitability of using the Model to justify claims. Further, there is no mention of a communication protocol for changes to the model or BIM execution plans.

Interoperability The contract only requires the Contractor's design documents to be submitted in a proprietary format such as PDF or microstation. There are no specific protocols for the transfer of information, responsibility or auditing requirements all critical components for ensuring a high degree of interoperability.

Legislation and The legislative jurisdiction is detailed in the conditions and that the transfer of information electronically is Judicial

Precedence permitted. The concepts of privity and third party reliance are not considered by the contract.

Professional There is a clear delineation of design responsibilities between the Contractor and the Principal. There are Liability clearly defined design liabilities, but no consideration for the contribution of non-professionals or the delegation of design. The Contractor is responsible for completing the design and the Principal is responsible for any design components it has included as a contract document. There are no mechanisms for allocating ultimate responsibilities for collaborative design contributions. In addition, there are no requirements for design professional licensing or the consequences of software generated design liabilities. The Contract does require the Contractor to hold current professional liability insurance but the inclusion of BIM in this policy is uncertain.

Public Sector The contract only requires the Contractor to obtain building permits, but does not detail the requirements Agency for maintaining an approval model or documents. The contract is silent on all other public sector requirements and the means of achieving approval in the event of hard copy submissions.

Risk Allocation The contract has adopted a cooperative risk allocation approach with a highly prescriptive distribution of roles and responsibilities. Risk planning is not an explicit requirement and the allocation of risk follows the traditional distribution structure with clearly defined responsibilities and liabilities. 


\section{Implications for Current and Future Practice}

As Governments continue to mandate the use of BIM, additional legal challenges will emerge and will require a considered response from legislators and contract drafters. This will require changes to current methodologies, processes and ways in which technology is used for delivering projects, and consequently changes to standard forms of contract.

\section{Changes to the GC21 contract}

In comparison with the challenges identified by Manderson et al, (2012) key changes to the GC21 contract could include:

- Adopting a collaborative procurement tool that includes a fair and equitable distribution of risk, responsibility and reward, in particular Professional Liability;

- Recognizing BIM as a contract document;

- Mandating the use of open standards; and

- The inclusion of high level BIM processes in the contract mechanisms.

One final recommendation is the inclusion of a BIM Execution Plan in the Contract Documents that is tailored to the requirements of the project.

\section{Methodology}

A key methodological challenge will be the transition to collaborative work practices including implementing relationship procurement methods. Within Australia, the use of relationship procurement, such as Alliancing Contracting, is restricted to large complex projects with no standard contract that can be easily implemented (Ingirige and Sexton, 2006; Rowlinson et al., 2006). Integrated Project Delivery (IPD) is widely accepted as an appropriate environment for BIM implementation (Parrott and Bomba, 2010). There are a number of Australian industry organisations, such as the Australian chapter of Buildingsmart and collaboration between Consult Australia and the Australian Institute of Architects that are working towards developing IPD delivery models (Australian Institute of Architects and Consult Australia, 2012; International Alliance for Interoperability, 2010). However, IPD may achieve only a limited acceptance in this country, a similar experience to that of America, due to the fragmented nature and the underlying adversarial culture of the AEC sector. Amendments to traditional contract form may encourage a transition to both the use of BIM and collaborative modes of contracting.

\section{Processes}

Similar to the methodology challenge, current industry processes are introverted and restrict the exchange of project information amongst project stakeholders unless contractually obliged to provide and then only with caveats that limit its application. Once again, a situation that is not conducive to collaboration. It is difficult to see how open and collaborative processes can be achieved in an industry where the collaborating organisation on the current project will be a competitor for the next project. One solution can be incorporating a mixture of BIM processes, suitable levels of protection for the Designer and Intellectual Property and appropriate punitive measures for non-performance in standard contracts or client briefs. At a global level, mandating the use of BIM for Government projects (Bew and Underwood, 2010; Eadie et al., 2013; Greenwood et al., 2008), as recommended by the Built Environment Industry Innovation Council (2010) and Productivity Council could provide the motivation for Private and Public Sector BIM adoption.

\section{Technology}

Viewed at its most basic, BIM authoring tools can generate a three dimensional parametric object based Model that has a range of applications throughout the facility lifespan. BIM 
Execution Plans typically address many of the technical issues faced by projects, such as interoperability and Level of Detail. While the actual technical requirements need not be detailed in the Conditions, including the Execution Plan as a contract document does give weight to its status and as a means of enforcing its requirements.

One major challenge facing organisations is the initial BIM adoption process. For many businesses, the costs of purchasing the software, hardware upgrades, staff training and changes to internal workflows significantly influence the adoption decision. These costs need to be recouped in some way. Ashcraft (2008) suggests amortization over several projects, but with the majority of companies in the AEC Sector employing less than fifteen people the costs of implementation may constitute a sizable percentage of the overall business operating costs. The justification for adoption may be overwhelming but the impact BIM adoption has on the profitability of the business may be detrimental to its short term viability in a volatile market.

\section{BIM Analysis Tool Validation and Future Directions}

This research was a pilot study of the current BIM legal challenges facing the AEC Sector. The evolution of the analysis tool is in the early phases of development and further refinement will consist of engagement with the wider AEC sector, particularly those stakeholders with BIM project experience, to identify additional issues and possible ranking of the challenges. This will determine which categories are critical for leading to the formation of a roadmap for contractual change. Other possibilities include the analysis of additional contracts and a comparison of the results.

\section{Conclusions}

As clients mandate BIM, standard contracts will need to address the legal challenges associated with BIM methodology, processes and technological implementation. This study focused on identifying the changes needed to a standard construction contract to enable the implementation of BIM. A comprehensive literature review identified ten legal challenges facing BIM implementation:

1. Compensation \& Consideration

2. Conditions of Contract

3. Data Security

4. Intellectual Property

5. ICT Protocols Processes \& Responsibilities
6. Interoperability

7. Legislation \& Judicial Precedence

8. Professional Liability

9. Public Sector Agency

10. Risk Allocation

These ten areas were used to develop a Qualitative Content Analysis coding frame that was then applied to a standard public sector contract (i.e. GC21). The results of the analysis identified a number of contract changes including:

- Adopting a collaborative procurement tool that includes a fair and equitable distribution of risk, responsibility and reward and in particular Professional Liability;

- Recognizing BIM as a contract document;

- Mandating the use of open standards; and

- The inclusion of BIM specific processes in the contract mechanisms.

Additional changes will be required to current methodologies, processes and technology that will need to be reflected in the conditions of contract. Further investigation is therefore required to refine the analysis tool, engage with industry to ensure all of the legal issues have been identified and then apply the enhanced analysis tool to other standard contracts. Other legal challenges will continue to emerge as BIM is further applied throughout the project delivery cycle as previously unthought-of applications are integrated into project delivery methods. 


\section{References}

Allen, G. and Helms, M., 2006. Linking strategic paractices and organizational performance to Porter's generic strategies. Business Process Management Journal, 12(4), pp.433-54. doi: http://dx.doi.org/10.1108/14637150610678069

Amor, R. and Faraj, I., 2001. Miconceptions about integrated project databases. Journal of Information Technology in Construction [online] [Accessed 20 January 2010].

Anumba, C.J. and Ruikar, K., 2002. Electronic commerce in construction--trends and prospects. Automation in Construction, 11(3), pp.265-75. doi: http://dx.doi.org/10.1016/S0926-5805(01)00087-5

Aranda-Mena, G., Crawford, J., Chevez, A. and Froese, T., 2009. Building information modelling demystified: does it make business sense to adopt BIM? International Journal of managing projects in business, 2(3), pp.419-33.

Arayici, Y., Coates, P., Koskela, L., Kagioglou, M., Usher, C. and O'Reilly, K., 2011. Technology adoption in the BIM implementation for lean architectural practice. Automation in Construction, 20(2), pp.189-95. doi: http://dx.doi.org/10.1016/j.autcon.2010.09.016

Arensman, D. and Ozbek, M., 2012. Building information modeling and potential legal issues. International Journal of Construction Education \& Research [online] [Accessed 22 November 2012].

Ashcraft, H., 2008. Building information modeling: Framework for collaboration. The Construction Lanyer [online] [Accessed 14 March 2011].

Australian Institute of Architects and Consult Australia, 2012. BIM/IPD Aust [online] Sydney: AIA and Consult Australia. Available at: http://www.bim.architecture.com.au/.

Azhar, S., Khalfan, M. and Masqsood, T., 2012. Building information modeling (BIM): now and beyond. Australasian Journal of Construction Economics and Building [online] [Accessed 12 November 2012].

Bailey, I. and Bell, M., 2011. Construction law in Australia. 3rd ed. Sydeny: Thomson Reuters (Professional) Australia Ltd.

Beard, C., 2006. Implementing building product models: perspectives from an Australian construction project, School of Architecture and Built Environment, University of Newcastle.

Becerik-Gerber, B. and Kensek, K., 2010. Building information modeling in architecture, engineering, and construction; emerging research directions and trends. Journal of Professional Issues in Education and Practice, 136(3), pp.139-47. doi: http://dx.doi.org/10.1061/(ASCE)EI.1943-5541.0000023

Berelson, B., 1971. The analysis of communication content. New York: Hafner.

Bew, M. and Underwood, J., 2010. Delivering BIM to the UK market place. In: J. Underwood and U. Isikdag eds. Building information modeling and construction informatics concepts and technologies. New York: Information Science Reference.

Boyatzis, P., 1997. Transforming qualitative information: Thematic analysis and code development. Oxford: Sage Publications.

Bryde, D., Broquetas, M. and Volm, J.M., 2013. The project benefits of Building Information Modelling (BIM). International journal of project management, 31(7), pp.971-80. doi: http://dx.doi.org/10.1016/j.ijproman.2012.12.001

Buildingsmart, 2012. The BIM evolution continues with OPEN BIM. [Accessed 25 March 2014].

Built Environment Industry Innovation Council, 2010. Issues paper: digital modelling and the built environment. Canberra: Australian Government: Department of Innovation Industry, Science and Research.

Chartered Instituteof Building, 2013. CIOB Contract for use with complex projects. London: Chartered Instituteof Building.

CRC Construction Innovation, 2008. eContracting - security and legal issues [e-book]. Brisbane: CRC Construction Innovation [Accessed 10 November 2011].

Duyshart, B., Walker, D., Mohamed, S. and Hampson, K., 2003. An example of developing a business model for information and communication technologies (ICT) adoption on construction projects - the National Museum of Australia project. Engineering, Construction and Architectural Management, 10(3), pp.179-92. doi: http://dx.doi.org/10.1108/09699980310478430

Eadie, R., Browne, M., Odeyinka, H., McKeown, C. and McNiff, S., 2013. BIM implementation throughout the UK construction project lifecycle: An analysis. Automation in Construction, 36, pp.145-51. doi: http://dx.doi.org/10.1016/j.autcon.2013.09.001

Eastman, C., Teicholz, P., Sacks, R. and Liston, K., 2011. BIM bandbook a guide to building information modeling for owners managers designers engineers and contractors. 2nd ed. New Jersey: John Wiley \& Sons, Inc.

Egan, J., 1998. Rethinking construction. London: DETR.

Greenwood, D., Horne, M., Thompson, E., Allwood, C., Wernemyr, C. and Westerdahl, B., 2008. Strategic Perspectives on the Use of Virtual Reality within the Building Industries of Four Countries. Architectural Engineering and Design Management, 4(2), p.85. doi: http://dx.doi.org/10.3763/aedm.2008.0076

Greenwood, D., Lewis, S. and Lockley, S., 2010. Contractual issues in the total use of building information modelling. In: W113 - Special Track 18th CIB World Building Congress. Salford, United Kingdom, 10-13 May 2010.

Grilo, A. and Jardim-Goncalves, R., 2011. Challenging electronic procurement in the AEC sector: A BIM-based integrated perspective. Automation in Construction, 20(2), pp.107-14. doi: http://dx.doi.org/10.1016/j.autcon.2010.09.008 
Hartmann, T. and Fischer, M., 2008. Applications of BIM and burdles for widespread adoption of BIM 2007 AISC-ACCL econstruction roundtable event report. Stanford University. Stanford: Stanford University.

Haynes, D., 2009a. Reflections on some legal and contractual implications of building information modelling (BIM). Construction Watch [online] [Accessed 14 February 2011].

Haynes, D., 2009b. A tale of two exhibits- a comparison of the CD301 and E202 BIM exhibits. Construction Watch [online] [Accessed 14 March 2011].

Holzer, D., 2007. Are you talking to me? Why BIM alone is not the answer. In: 2007 Association of Architecture Schools Australasia Conference. Sydney, 15 October 2007: Univeristy of Technology Sydney.

Hughes, W. and Greenwood, D., 1996. The standardisation of contracts for construction. International Construction Law Review [online] [Accessed 28 March 2011].

Hurtado, K. and O'Connor, P., 2008. Contract issues in the use of building information modeling. International Construction Law Review [online] [Accessed 22 March 2011].

Ingirige, B. and Sexton, M., 2006. Alliances in construction Investigating initiatives and barriers for long-term collaboration. Engineering Construction and Architectural Management [online] [Accessed 14 March 2011]. doi: http://dx.doi.org/10.1108/09699980610690774

International Alliance for Interoperability, 2010. The National BIM Roadmap workshops [online] Brisbane: BuildingSMART. Available at: http://buildingsmart.org.au/recent-events.

Jensen, P.A. and Jóhannesson, E.I., 2013. Building information modelling in Denmark and Iceland. Engineering, Construction and Architectural Management, 20(1), pp.99-110. doi: http://dx.doi.org/10.1108/09699981311288709

Keung, C. and Shen, L., 2013. Measuring the Networking Performance for Contractors in Practicing Construction Management. Journal of Management in Engineering, 29(4), pp.400-6. doi: http://dx.doi.org/10.1061/(ASCE)ME.1943-5479.0000156

Khosrowshahi, F. and Arayici, Y., 2012. Roadmap for implementation of BIM in the UK construction industry. Engineering, Construction and Architectural Management, 19(6), pp.610-35. doi: http://dx.doi.org/10.1108/09699981211277531

Kog, Y.C., 2010. Legal issues of integrated network for construction real estate sector. Journal of Legal Affairs and Dispute Resolution in Engineering and Construction [online]. Available at: http://link.aip.org/link/?QLA/2/228/1.

Kuiper, L. and Holzer, D., 2013. Rethinking the contractual context for building information modelling in the australian built environment industry. Australasian Journal of Construction Economics and Building [online] [Accessed 24 December 2013].

Larson, D. and Golden, K., 2007. Entering the brave new world: an introduction to contracting for building information modeling. Mitchell Law Review, 75, pp.75-108.

Loots, P. and Charrett, D., 2009. Practical guide to engineering and construction contracts. CCH Australia Ltd.

Lowe, R. and Muncey, J., 2009. ConsensusDOCS 301 BIM Addendum. The Construction Lanyer [online] [Accessed 14 March 2011].

Manderson, A., Brewer, G., and Jefferies, M. (2012) A Taxonomy of the Legal and Contractual Issues Related to Building Information Modelling Integration. Proceedings of the Construction, Building and Real Estate Conference, COBRA - RICS,11-13 September, Arizona State University, US, pp401-411.

Mayring, P., 2004. Qualitative content analysis. In: U. Flick, E. von Kardoff and I. Steinke eds. A companion to qualitative research. London: Sage.

McAdam, B., 2010. Building information modelling: the UK legal context. International Journal of Law in the Built Environment, 2(3), pp.246-59. doi: http://dx.doi.org/10.1108/17561451011087337

McGraw Hill Construction, 2014. The business value of BIM in Australia and New Zealand: How building information modelling is transforming the design and construction industry. Bradford: McGraw Hill Construction.

New South Wales Procurement, 2012. Performance management system [online] Sydney: New South Wales Government. Available at: https://www.procurepoint.nsw.gov.au/before-you-buy/procurement-systemconstruction/performance-management/performance-management-system.

NSW Department of Commerce, 2012 Overview and summary of the specific GC21 provisions.Sydney: NSW Government.

NSW Department of Public Works and Services, 1998. Information technology in construction making IT work. Sydney: NSW Department of Pubilc Works and Services.

O'Brien, T., 2007. Building information modeling sailing on uncharted waters. In: American Bar Association Forum on the Construction Industry, October 25-26, 2007.

Olsen, D. and Taylor, M., 2010. Building information models as contract documents: common practice for the U.S. construction industry - A preliminary report. In: 18th CIB World Building Congress- W113 Law and Dispute Resolution. Salford, United Kingdom, 13 May 2010: CIB W113 Law and Dispute Resolution.

Parrott, B. and Bomba, B., 2010. Integrated project delievery and building information modeling: a new breed of contract. Precast/Prestressed Concrete Institute Journal, 12(1).

Phua, F.T.T. and Rowlinson, S., 2004. How important is cooperation to construction project sucess? A grounded empirical qualification. Engineering Construction and Architectural Management [online] [Accessed 14 March 2011]. doi: http://dx.doi.org/10.1108/09699980410512656 
Porwal, A. and Hewage, K., 2013. Building information modeling (BIM) partnering framework for public construction projects. Automation in Construction [online] [Accessed 20 Febuary 2013]. doi: http://dx.doi.org/10.1016/j.autcon.2012.12.004

Rezgui, Y., Beach, T. and Rana, O., 2013. A governance approach for BIM management across lifecyle and supply chains using mixed-modes of information delivery. Journal of Civil Engineering and Management, 19(2), pp.239-58. doi: http://dx.doi.org/10.3846/13923730.2012.760480

Rowlinson, S., Cheung, F., Simons, R. and Rafferty, A., 2006. Alliancing in Australia - no-litigaiton contracts: A tautology? Journal of Professional Issues in Engineering Education and Practice [online] [Accessed 21 January 2011]. doi: http://dx.doi.org/10.1061/(ASCE)1052-3928(2006)132:1(77)

Royal Commission into the Building and Construction Industry, 2002 Overview of the nature and operation of the building and construction industry: Discussion paper 1.Canberra: Commonwealth of Australia.

Schreier, M., 2013. Qualitative content analysis in practice. London: Sage Publications Ltd.

Sebastian, R., 2010. Breaking through business and legal barriers of open collaborative processes based on building information modelling (BIM). In: 18th CIB World Building Congress- W113 Law and Dispute Resolution. Salford, United Kingdom, 13 May 2010: CIB W113 Law and Dispute Resolution.

Sebastian, R., 2011. Changing roles of the clients, architects and contractors through BIM. Engineering Construction and Architectural Management [online] [Accessed 15 April 2011]. doi: http://dx.doi.org/10.1108/09699981111111148

Simonian, L. and Korman, T., 2010. Legal considerations in the United States associated with building information modeling. In: COBRA 2010 CIB W113 Law \& Dispute Resolution. Paris.

Sweet, J. and Schneier, M., 2013. Legal aspects of architecture, engineering and the construciton process. 9th ed. Stamford: Cengage Learning.

Thomson, D. and Miner, R., 2006. Building Information Modeling - BIM: Contractual Risks are Changing with Technology [online]. Available at: http://www.aepronet.org/Pages/Guest $\% 20$ Essays.aspx.

Weber, R., 1990. Basic Content Analysis. California: Sage Publications.

Wheatley, B. and Brown, T., 2007. An introduction to building information modeling. The Construction Lawyer [online] [Accessed 10 December 2010].

Wong, A., Wong, F. and Nademm, A., 2011. Government roles in implementing building information modelling systems Comparison between Hong Kong and the United States. Construction Innovation [online] [Accessed 21 January 2011]. doi: http://dx.doi.org/10.1108/14714171111104637 